\title{
Conversion of the Pathogenic Fungus Colletotrichum magna to a Nonpathogenic, Endophytic Mutualist by Gene Disruption
}

\author{
Regina S. Redman, ${ }^{1,2}$ Judith C. Ranson, ${ }^{1}$ and Rusty J. Rodriguez ${ }^{1,2}$ \\ ${ }^{1}$ Western Fisheries Research Center, Biological Resources Division, USGS, 6505 N.E. 65th St., Seattle, \\ WA 98115, U.S.A.; ${ }^{2}$ Department of Botany, University of Washington, Seattle 98195-5325, U.S.A. \\ Accepted 4 August 1999.
}

\begin{abstract}
Hygromycin-resistant transformants of the cucurbit pathogen Colletotrichum magna (teleomorph: Glomerella magna) were generated by restriction enzyme-mediated integration (REMI) transformation. A rapid pathogenicity assay involving watermelon (Citrullus lanatus) seedlings was developed and 14,400 REMI transformants were screened and assessed for their ability to cause disease, colonize plant tissues, and confer disease resistance against wild-type $C$. magna. A total of 176 nonpathogenic REMI mutants capable of colonizing cucurbit plants were isolated and assigned to three groups based on their ability to confer disease resistance: phenotype $A, 80$ to $100 \%$ disease protection; phenotype $\mathrm{B}, \mathbf{1 0}$ to $65 \%$ disease protection; and phenotype $\mathrm{C}, 0$ to $4 \%$ disease protection. Molecular and genetic analyses of one REMI mutant (R1) indicated that the nonpathogenic phenotype A resulted from a single-site integration. R1 showed a 1:1 segregation of hygromycin resistance and nonpathogenicity and all hygromycin-resistant progeny were nonpathogenic. The integrated vector and $5.5 \mathrm{~kb}$ of flanking fungal genomic DNA were isolated from $R 1$ and designated pGMR1. To verify that pGMR1 contained pathogenicity gene sequences, a wild-type isolate of $C$. magna was transformed with pGMR1 to induce gene disruptions by homologous integration. Approximately $47 \%$ of the pGMR1 transformants expressed phenotype $A$, indicating homologous integration and gene disruption.
\end{abstract}

Additional keywords: plant pathogen, plasmid rescue.

Colletotrichum magna is one of the causal agents of anthracnose disease on cucurbit plants (Jenkins and Winstead 1964). The disease process of fungi belonging to this genus begins with the adhesion of spores to the plant cell surface, spore germination, appressorium formation, and penetration into the first subcuticular cell, followed by production of secondary hyphae that quickly disseminate throughout the plant,

Corresponding author: Rusty Rodriguez

E-mail: Rusty_Rodriguez@usgs.gov

This article is in the public domain and not copyrightable. It may be freely reprinted with customary crediting of the source. The American Phytopathological Society, 1999. causing plant cell death and hence disease symptoms (Bailey et al. 1992). Although many studies have focused on the developmental, biochemical, and molecular analyses of plantpathogen interactions, the genetic basis for the disease process is still largely undefined (Sweigard et al. 1998; Jackson and Taylor 1996; Hammond-Kosack and Jones 1996; Kuc 1990; Keen 1986; Dickman and Patil 1986; Hammerschmidt et al. 1982, 1984).

To understand the mechanisms and processes involved in pathogenicity, a nonpathogenic mutant of $C$. magna was generated through UV mutagenesis and denoted path-1 (Freeman and Rodriguez 1993). The mutant path-1 was capable of colonizing cucurbit plants without causing disease. Once plants were colonized, they were protected from disease when exposed to C. magna, Fusarium oxysporum (Freeman and Rodriguez 1993, 1992), and C. orbiculare (Redman et al. 1999). Genetic analysis of path-1 indicated that the mutation of a single locus allowed conversion of a plant pathogen to a nonpathogenic, endophytic mutualist (Freeman and Rodriguez 1993). Analysis of plant biochemical indicators of localized (peroxidase, phenylalanine ammonia-lyase, and lignin) and systemic (salicylic acid) "plant defense responses" collectively indicated that disease protection in path-1 colonized plants was nonsystemic and correlated with the ability of these plants to mount a defense response more rapidly and to greater levels than plants exposed to $C$. magna alone (Redman et al. 1999). We propose that the protection from disease afforded to plants colonized by the path-1 mutant is an endophyteassociated response (EAR) and involves an interaction between the mutant and plant resulting in the priming of the host defense systems. Once primed, the host defenses are activated rapidly and to high levels when the plants are challenged with virulent fungi (Redman et al. 1999).

The goal of this study was to identify the gene(s) that when mutated resulted in conversion of wild-type $C$. magna to a nonpathogenic endophyte, and to determine the genetic complexity of this phenomenon. Although there are several different approaches for obtaining the gene(s) of interest, earlier studies conducted in our laboratory indicated that REMI (restriction enzyme-mediated integration) transformation was a viable option for the efficient generation of insertional mutants in Colletotrichum spp. (Redman and Rodriguez 1994). There are many advantages to REMI transformation. Transformation efficiencies are often elevated by the REMI proto- 
col. Gene(s) of interest are tagged by the transformation vector and may be isolated by "plasmid rescue," and retrieved plasmids with flanking genomic DNA may be used for gene disruption studies. In addition, utilization of REMI for the successful generation of mutants and gene isolation has been shown in many species including Dictyostelium discoideum (Kuspa and Loomis 1992, 1994), Neurospora crassa (Kang and Metzenberg 1993), Ustilago maydis (Bolker et al. 1995), Alternaria alternata (Akamatsu et al. 1997), Candida albicans (Brown et al. 1995), Coprinus cinereus (Granado et al. 1997), and Magnaporthe grisea (Sweigard et al. 1998; Shi et al. 1995).

In this study, we present the isolation and characterization of 176 nonpathogenic REMI mutants. One of the genes responsible for the nonpathogenic phenotype was isolated from REMI mutant R1 and its function verified through gene disruption studies in a wild-type isolate of $C$. magna. The significance of the R1 mutant in defining the genetic basis of fungal symbiotic lifestyles is discussed.

\section{RESULTS}

Isolation and characterization of nonpathogenic mutants.

Optimization of parameters involved in the transformation protocol, such as concentrations of cell wall-degrading enzymes, regeneration buffer, and length of time of regeneration, contributed to increase the efficiencies from 0-50 (Redman and Rodriguez 1994) to 1,000-2,000 transformants $\mu \mathrm{g}^{-1}$ of plasmid DNA in C. magna (data not shown). REMI transformation was optimized by the addition of 0 to $200 \mathrm{U}$ of different restriction enzymes (XbaI, HindIII, SacI, SalI, NdeI, ApaI, $P v u \mathrm{II})$ and linearized plasmid (digested with the same restriction enzyme added to the transformation reaction) to the protoplast transformation cocktail (data not shown). The highest transformation efficiencies (2,000 to 3,000 transformants $\mu \mathrm{g}^{-1}$ of plasmid DNA) were obtained with reactions containing 5 $\mu \mathrm{g}$ of HindIII-linearized pHA1.3 (Powell and Kistler 1990; Rodriguez and Redman 1992) and 40 to 80 U of HindIII restriction enzyme. All subsequent REMI transformations were conducted under these optimized conditions.

Over 20,000 REMI transformants were generated with a vector that conferred hygromycin resistance (pHA1.3) and 14,400 transformants that exhibited stable hygromycin resistance were screened for pathogenicity. Each transformant was individually screened for its ability to cause disease on three anthracnose-susceptible watermelon seedlings. Transformants (288) were identified that did not cause plant disease. These were subjected to a secondary screening that involved assessing their ability to colonize 30 anthracnose-susceptible watermelon seedlings. From the 288 putative nonpathogenic transformants, 176 were identified that did not cause disease in the secondary screening but did colonize cucurbit plants. The remaining 112 nonpathogenic REMI mutants appeared to be defective in the ability to colonize plants.

To determine if any of the nonpathogenic REMI mutants expressed the same phenotype as the original path-1 mutant, the mutants were screened for the ability to confer disease resistance. Anthracnose-susceptible watermelon seedlings were colonized with REMI mutants and then exposed to lethal concentrations of spores of the wild-type C. magna isolate L2.5 (Freeman and Rodriguez 1992, 1993). The 176 nonpathogenic
REMI mutants were placed into one of three phenotypic categories based on disease protection: phenotype A, 60 REMI mutants affording 80 to $100 \%$ disease protection; phenotype B, 55 REMI mutants affording 10 to $65 \%$ disease protection; and phenotype C, 61 REMI mutants affording 0 to $4 \%$ disease protection (Fig. 1). It is possible that the mutants placed at the extremes of the phenotypic classes may be improperly designated. However, this would apply to a low percentage of the REMI mutants.

The ability of REMI mutants expressing phenotypes A, B, and $\mathrm{C}$ to protect plants against disease is shown in Figure 2. Initial characterization of the REMI mutants was performed to assess the three nonpathogenic phenotypes for differences in growth rates, initial developmental processes (spore adhesion, germination, appressorial formation, and plant colonization), or extracellular enzyme production (protease and cellulase). Extensive characterization of these physiological attributes indicated that the variation between the REMI mutants and the wild-type isolate L 2.5 was $\leq 10 \%$ (data not shown). In fact, the only notable difference between the nonpathogenic mutants and the wild type was that the mutants generally produced less pigmentation (data not shown).

It was of interest to determine if the variation in disease protection conferred by the nonpathogenic phenotypes was due to differences in colonization ability. The colonization of plants by REMI mutants representing each phenotype was assessed 7 days after inoculation (Table 1). Although the plant colonization studies are a qualitative measure of colonization, these studies revealed that all of the 176 nonpathogenic REMI mutants were able to colonize the roots and majority of plant

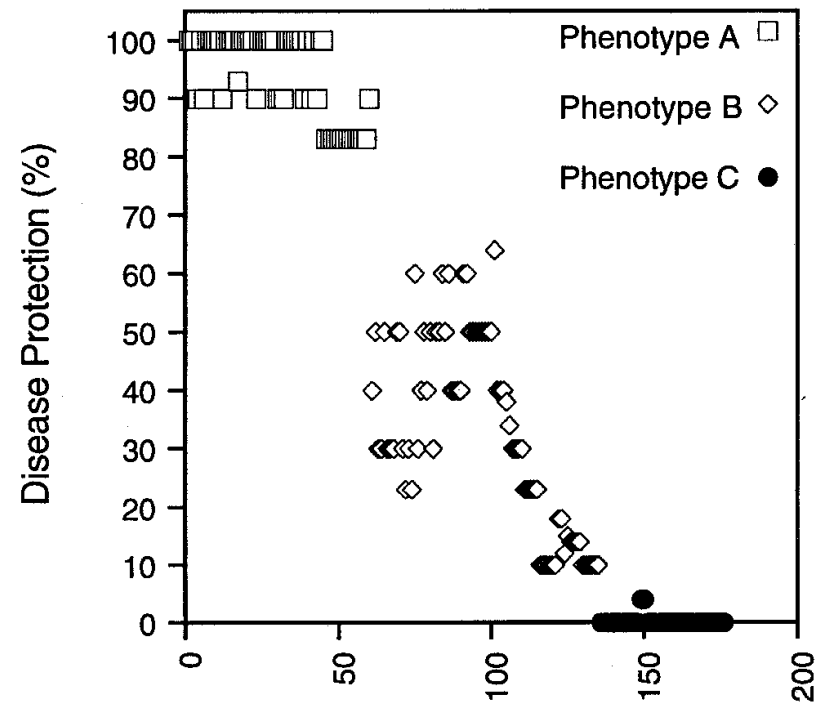

Fig. 1. Distribution of nonpathogenic restriction enzyme-mediated integration (REMI) mutant phenotypes in relation to disease protection level conferred to susceptible Crimson Sweet watermelon plants. REMI mutants expressing phenotypes A, B, and C conferred 80-100, 10-65, and 0-4\% protection against Colletotrichum magna wild-type isolate L2.5, respectively. Data indicate disease protection levels (as percentage of 30 mutant colonized seedlings that survived exposure to lethal concentrations of wild-type L2.5 spores) conferred by each of the individual 176 REMI mutants. 
stem sections. There was little variation in the extent and pattern of colonization in the middle (M) and upper (U) stem sections by REMI phenotypes A (M, 92\% and U, 22\%) B (M, $93 \%$ and $\mathrm{U}, 22 \%)$, and $\mathrm{C}(\mathrm{M}, 98 \%$ and $\mathrm{U}, 5 \%)$.

\section{Molecular analysis of nonpathogenic REMI mutants.}

Genomic DNA from 20 REMI mutants including representatives of groups A, B, and C was digested with XhoI, which does not digest pHA1.3, and with HindIII, which digests once within pHA1.3, and subjected to Southern blot analysis (data not shown). Figure 3 shows three representative REMI mutants of phenotype A (Tx01, Tx02, and Tx03) exhibiting varying integration patterns. There appeared to be three types of integration events involving either single-site integration into HindIII sites (Tx01); multiple integrations into multiple HindIII sites (Tx02); and single and/or tandem integration(s) into HindIII, non-HindIII, or modified HindIII sites made non-

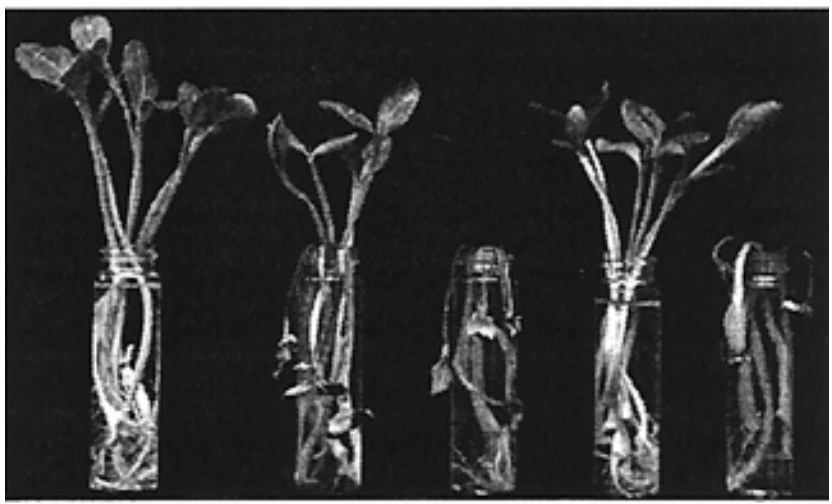

Fig. 2. Seven-day-old, anthracnose-susceptible watermelon plants exposed to the following five treatments (left to right): treatment 1, colonization with restriction enzyme-mediated integration (REMI) mutant phenotype A (R1) for $48 \mathrm{~h}$ followed by challenge with the Colletotrichum magna wild-type isolate $\mathrm{L} 2.5$; treatment 2 , colonization with REMI phenotype B (R4) for $48 \mathrm{~h}$ followed by challenge with L2.5; treatment 3, colonization with REMI phenotype C (R5) for $48 \mathrm{~h}$ followed by challenge with $\mathrm{L} 2.5$; treatment 4 , water control; and treatment 5 , water control plants challenged with L2.5. Challenge conditions involved exposure to lethal concentrations $\left(3.0 \times 10^{6}\right.$ conidia ml $\left.{ }^{-1}\right)$ of isolate L2.5. Plant mortality was assessed after 5 to 7 days and was 0,33 , 100,0 , and $100 \%$ for treatments $1,2,3,4$, and 5, respectively.

Table 1. Pathogenicity and colonization of Colletotrichum magna restriction enzyme-mediated integration (REMI) mutants

\begin{tabular}{lccccc}
\hline \multirow{2}{*}{$\begin{array}{l}\text { REMI } \\
\text { mutants } \\
\text { (no.) }^{\mathbf{b}}\end{array}$} & \multicolumn{4}{c}{ Plant colonization $^{\mathbf{a}}$} \\
\cline { 2 - 6 } & Phenotype $^{\mathbf{c}}$ & ${\text { Root }(\boldsymbol{\%})^{\mathbf{d}}}^{\mathbf{2}}$ & $\begin{array}{c}\text { Lower } \\
\text { stem }(\boldsymbol{\%})^{\mathbf{d}}\end{array}$ & $\begin{array}{c}\text { Middle } \\
\text { stem (\%) }\end{array}$ & $\begin{array}{c}\text { Upper } \\
\text { stem (\%) }\end{array}$ \\
\hline 60 & A & 100 & 100 & 92 & 22 \\
55 & B & 100 & 100 & 93 & 22 \\
61 & C & 100 & 100 & 98 & 5 \\
\hline
\end{tabular}

${ }^{a}$ Three Crimson Sweet seedlings colonized by exposing lower stems and roots to a spore suspension of each of 176 REMI mutants.

${ }^{b}$ Number of nonpathogenic REMI mutants screened in each phenotypic group.

${ }^{c}$ Phenotypes based on percent disease protection (number of mutantcolonized plants surviving pathogen challenge) afforded to 30 anthracnose-susceptible watermelon seedlings by the mutants: (A) 80 to $100 \%$; (B) 10 to $65 \%$; and (C) 0 to $4 \%$.

${ }^{\mathrm{d}}$ Data indicate percent nonpathogenic REMI mutants from each phenotype recovered from various plant tissue sections 7 days after inoculation. functional by the integration process (Tx03). Single-site integration was represented by REMI mutant Tx01, in which one vector-sized and one larger than vector-sized band (representing pHA1.3 and surrounding flanking DNA) were observed in HindIII and XhoI digestions, respectively (Fig. 3, lanes 1 and 2). Multiple integration events into genomic HindIII sites were observed with TX02 as a single vectorsized band in HindIII-digested genomic DNA and as multiple bands larger than vector size in XhoI digestions (Fig. 3, lanes 3 and 4). Integration of the plasmid through single and/or multiple integration event(s) into HindIII and either modified HindIII or non-HindIII sites was observed with Tx03 as multiple bands that were vector-sized and/or larger than vectorsized in HindIII- and XhoI-digested genomic DNA (Fig. 3, lanes 5 and 6). Our molecular studies indicated that $70 \%$ of the initial 20 REMI mutants chosen for analysis arose through single-site integration events and approximately half of these mutants arose through integration at HindIII sites.

\section{Selection of an REMI mutant for genetic and molecular studies.}

To optimize our chances of isolating the disrupted sequences responsible for generating nonpathogenic mutants, REMI mutant R1 expressing phenotype A was chosen for the remainder of these studies. Mutant R1 exhibited colonization of the lower, middle, and upper stem and root tissues comparable to all other phenotype A mutants, and conferred $100 \%$ disease protection to plants. In addition, REMI mutant R1 had the same Southern blot hybridization profile as TX01 (Fig. 3, lanes 1 and 2), indicating that R1 resulted from a single integration event into the same HindIII site as TX01.

\section{Segregation analysis.}

Genetic segregation analyses were performed to test whether the integration of pHA1.3 was likely to be responsible for the nonpathogenic phenotype for REMI mutant R1. Analysis of 86 progeny representing four perithecia derived from crosses between the wild-type C. magna isolate (Gm16) and REMI mutant R1 indicated approximately a 1:1 segregation ratio for hygromycin resistance:sensitivity, and patho-

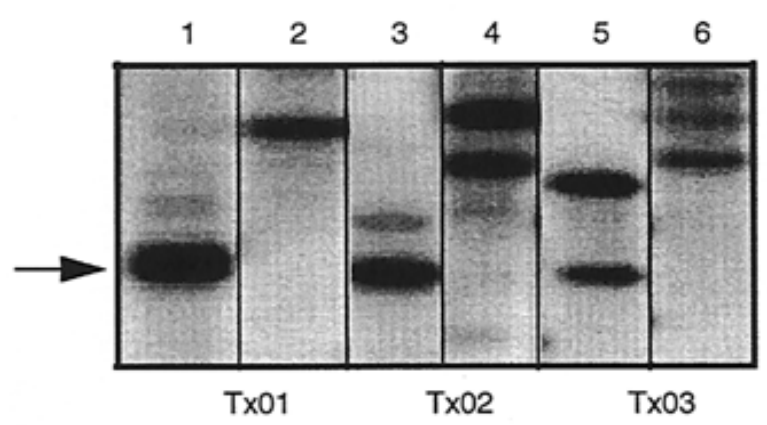

Fig. 3. Southern blot analysis of genomic DNA from three representative restriction enzyme-mediated integration (REMI) mutants of phenotype A possessing single (Tx01 [lanes 1 and 2]) and multiple (Tx02 [lanes 3 and 4]) integrations into HindIII restriction enzyme sites, and single and/or tandem integration(s) into HindIII, and either non-HindIII or modified HindIII sites (Tx03 [lanes 5 and 6]). Samples were digested with HindIII (lanes 1, 3, and 5) or XhoI (lanes 2, 4, and 6) restriction enzymes and probed with ${ }^{32} \mathrm{P}$-labeled, HindIII-linearized pHA1.3 vector. Arrow denotes linear vector-sized DNA $(6.4 \mathrm{~kb})$. 
genicity:nonpathogenicity (Table 2). In addition, all of the hygromycin-resistant progeny were nonpathogenic and all of the hygromycin-sensitive progeny were pathogenic (data not shown). Exact chi-square tests performed with StatXact 3.1 for Windows (Cytel Software, Cambridge, MA) showed no significant deviation from a 1:1 ratio in the Gm16 $\times \mathrm{R} 1$ crosses (Table 2). Therefore, REMI mutant R1 was an appropriate candidate for the reisolation of the integrated vector and flanking genomic DNA by "plasmid rescue" (below).

\section{Plasmid rescue, transformation, and gene disruption of C. magna.}

To recover pHA1.3 and flanking fungal genomic sequences from the integration site, genomic DNA of REMI mutant R1 was digested with XhoI (an enzyme that does not digest pHA1.3), ligated, and transformed into Escherichia coli. The recovered plasmid, designated pGMR1, was approximately $12.0 \mathrm{~kb}$ in length and contained approximately $5.5 \mathrm{~kb}$ of flanking genomic DNA. To confirm that the retrieved genomic DNA contained sequences related to pathogenicity, pGMR1 was transformed into the wild-type $C$. magna isolate L2.5 in an attempt to disrupt the wild-type copy of the sequences responsible for the R1 mutation. If pGMR1 integrated by homology then the disrupted gene sequences in pGMR1 would replace the wild-type copy and generate nonpathogenic mutants. Following transformation with pGMR1, 107 hygromycin-resistant transformants were screened for pathogenicity and colonization of anthracnose-susceptible watermelon plants. Approximately 47\% (50 mutants designated GkMa150) of the 107 transformants were nonpathogenic, colonized plant tissues, and expressed disease protection phenotype A (data not shown). The remaining 57 hygromycin-resistant transformants were pathogenic and were designated EMa157. When wild-type $C$. magna was transformed with the pHA1.3 vector alone, $100 \%$ of the hygromycin-resistant transformants (100 screened) were pathogenic (data not shown). These results indicated that the pGMR1 vector contained fungal genomic sequences that were involved in pathogenicity.

\section{Molecular analysis of targeted gene disruption and ectopic integration transformants.}

To characterize the molecular basis of REMI phenotype A, genomic DNA from REMI mutant R1, wild-type isolate L2.5, gene disruption transformants GkMa-1 and GkMa-2, and pathogenic transformants EMa-1 and EMa-2 was digested with $X h o I$ and analyzed by hybridization analysis with pGMR1 as the probe (Fig. 4, lanes 1-6, respectively). Single hybridization bands of approximately $12.0 \mathrm{~kb}$ for REMI mutant R1 (lane 1) and $5.5 \mathrm{~kb}$ for wild-type L2.5 (lane 2) indicated that pHA1.3 (6.4 kb in size) had integrated into a single HindIII site, resulting in the disruption of a pathogenicity-

Table 2. Segregation analysis of nonpathogenic phenotype A

\begin{tabular}{|c|c|c|c|c|c|c|}
\hline \multirow[b]{3}{*}{ Phenotype } & \multirow{2}{*}{\multicolumn{2}{|c|}{$\begin{array}{l}\text { Parental } \\
\text { isolates }^{\mathrm{a}}\end{array}$}} & \multirow{3}{*}{$\begin{array}{c}\text { Progeny } \\
\text { Gm16 } \\
\times \text { R1 }\end{array}$} & \multicolumn{3}{|c|}{ Segregation analysis } \\
\hline & & & & \multirow[b]{2}{*}{ Ratio } & \multirow{2}{*}{$\begin{array}{c}\text { Chi- } \\
\text { square }\end{array}$} & \multirow{2}{*}{$\begin{array}{c}P \\
\text { value }\end{array}$} \\
\hline & Gm16 & R1 & & & & \\
\hline & & $\mathrm{R}$ & & 0. & & \\
\hline athogenicity & + & - & $40-: 46+$ & 0.87 & 0.419 & 0.590 \\
\hline
\end{tabular}

${ }^{a} \mathrm{~S}=$ hygromycin sensitive; $\mathrm{R}=$ hygromycin resistant.

${ }^{\mathrm{b}}$ Assessed 7 days after inoculation of plants with conidia. related DNA sequence. The nonpathogenic pGMR1 transformants GkMa-1 and GkMa-2 had the same hybridization pattern as REMI R1, indicating that pGMR1 had integrated by homology into the same site as pHA1.3 had in REMI R1. In contrast, both pathogenic pGMR1 transformants EMa-1 and EMa-2 had two hybridizing bands, one at $5.5 \mathrm{~kb}$ as observed with wild-type L 2.5 , and additional bands at $>8 \mathrm{~kb}$. These results indicated that pGMR1 had integrated ectopically in EMa-1 and EMa-2.

\section{DISCUSSION}

A number of factors produced by plant-pathogenic fungi, such as extracellular enzymes and toxins, have been implicated as key components involved in plant disease. However, the exact mechanisms and/or the genetic and biochemical factors are undefined (Jackson and Taylor 1996; Madamanchi and Kuc 1991; Keen 1986; Kolattukudy 1985; Ciuffetti et al. 1983). Production of gene disruption mutants through REMI mutagenesis provides a powerful tool to investigate genes encoding factors involved in the disease process. In order to understand the basis of pathogenicity in Colletotrichum spp., 14,400 REMI mutants were screened and 176 nonpathogenic endophytic mutants were obtained. Although all 176 REMI mutants were nonpathogenic endophytes, approximately $34 \%$ could be defined as mutualists, $35 \%$ as commensals, and $31 \%$ as having an intermediate phenotype based on disease protection.

Molecular studies of 20 nonpathogenic REMI transformants by Southern blot analysis indicated that approximately $70 \%$ of the REMI mutants (including REMI R1) resulted from a single integration event (data not shown). Genetic segregation studies showed a 1:1 segregation ratio of the nonpathogenic and hygromycin resistance phenotypes, which confirmed that the disruption of a single gene required for pathogenesis occurred in REMI R1. More importantly, the integrated trans-

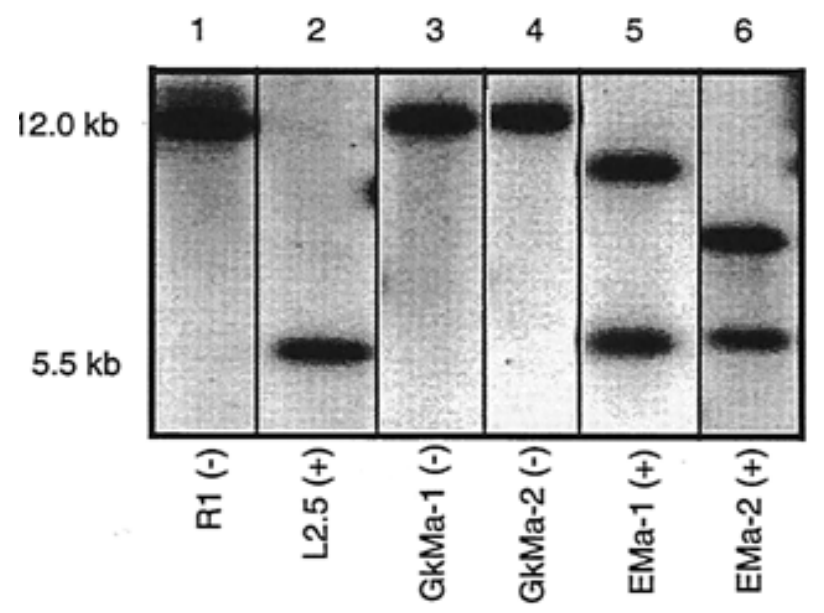

Fig. 4. Hybridization analysis of genomic DNA from nonpathogenic restriction enzyme-mediated integration (REMI) R1 (lane 1), wild-type isolate L2.5 (lane 2), nonpathogenic pGMR1 gene disruption transformants GkMa-1 (lane 3) and GkMa-2 (lane 4), and pathogenic ectopic pGMR1 integration transformants EMa-1 (lane 5) and EMa-2 (lane 6). DNA was digested with XhoI (does not digest pHA1.3) and probed with ${ }^{32} \mathrm{P}$-labeled, linearized pGMR1 as the probe. DNA size in kilobases $(\mathrm{kb})$ indicated on left. + and - denote pathogenic and nonpathogenic phenotypes, respectively, of fungal isolates on watermelon plants. 
formation vector and flanking genomic DNA were reisolated from REMI mutant R1, designated pGMR1, and tested to verify the presence of a disrupted pathogenicity gene through function. When pGMR1 was transformed into the wild-type isolate L2.5, the plasmid integrated by homology in approximately $47 \%$ of the transformants, disrupting sequences responsible for pathogenicity, and converting the transformants into nonpathogenic, endophytic mutualists. These results in conjunction with hybridization analysis indicated that homologous integration and gene disruption can occur at high frequencies in this species and confirmed that the flanking genomic sequences in pGMR1 contained pathogenicity gene sequences. Future studies will involve "plasmid rescue" of integrated vector and flanking DNA from representative REMI phenotypes $\mathrm{A}, \mathrm{B}$, and $\mathrm{C}$.

The nonpathogenic mutations described in this study provide insight into the genetic basis of fungal symbiotic lifestyles. The fact that single gene disruptions can alter fungal lifestyles between mutualism, commensalism, and pathogenesis suggests that these genes may represent highly conserved, fundamental aspects of plant-fungal symbioses. More importantly, this phenomenon may reflect the genetic simplicity and flexibility that allow coevolving organisms to achieve an equilibrium of intimate coexistence. It may also reflect a fine balance associated with maintaining nondestructive plantfungal associations, a balance that may be altered by environmental conditions, habitat alterations, or transportation of plants to new environments. It is well documented that environmental stress may increase the occurrence and severity of plant diseases. It is possible that the potential genetic simplicity of fungal symbiotic lifestyles may allow fungi to optimize their survival under varying environmental conditions even if that means converting from a mutualist to a pathogen. Regardless of this speculation, this system provides a unique opportunity to better understand the ecology, evolution, genetics, and biochemistry of plant-fungal symbioses.

\section{MATERIALS AND METHODS}

\section{Fungal strains, media, and plant cultivar.}

The pathogenic wild-type isolates L2.5 and Gm16 of Colletotrichum magna were obtained from S. Brown and O. C. Yoder (Cornell University, New York). Fungi were cultured on either liquid or solid modified Mathur's (MS) (Tu 1985) and/or hygromycin (HM) media containing $100 \mu \mathrm{g} \mathrm{ml}^{-1}$ of ampicillin and hygromycin, respectively, as previously described (Redman and Rodriguez 1994). Seeds of Crimson Sweet, an anthracnose-susceptible watermelon cultivar, were purchased from Petoseed (Woodland, CA).

\section{REMI transformation.}

Transformations were carried out as previously described (Redman and Rodriguez 1994) with the following exceptions: production of protoplasts was carried out in OM buffer (1.2 M $\mathrm{MgSO}_{4}, 10 \mathrm{mM} \mathrm{NaPO}$, $\left.\mathrm{pH} 5.8\right)$ containing $3.5 \mathrm{mg} \mathrm{ml}^{-1}$ of Novozyme 234 (Novonordisk, Bagsvaerd, Denmark), $3.5 \mathrm{mg}$ $\mathrm{ml}^{-1}$ of Lysing enzyme (Sigma, St. Louis, MO), and $100 \mathrm{U}$ $\mathrm{ml}^{-1}$ of $\beta$-glucuronidase; protoplast regeneration media contained $0.6 \mathrm{M}$ Sucrose, $0.1 \%$ casamino acids, and $0.1 \%$ yeast extract, ( $\mathrm{pH}$ 5.3); regeneration time was extended to 24 to 72 h; plasmid pHA1.3 (Powell and Kistler 1990; Rodriguez and
Redman 1992) was linearized with HindIII, and 40 to $80 \mathrm{U}$ of restriction enzyme was added to carry out REMI protoplast transformation reactions.

To single-spore purify the transformants, conidia from each REMI transformant were diluted in $1 \mathrm{ml}$ of sterile, distilled water, spread plated on MS medium, and allowed to germinate overnight. A single spore from each transformant was picked and plated onto HM selection medium. All REMI transformants were selected for and maintained on HM selection medium.

\section{Stability of REMI transformants.}

The stability of transformants was assessed by serial transfer of mycelial plugs of representative REMI transformants onto HM media containing or devoid of $100 \mu \mathrm{g} \mathrm{ml}^{-1}$ of hygromycin every 2 weeks. Stability was assessed by the expression of hygromycin resistance after transformants had been serially transferred in the absence of selection for 6 weeks. REMI transformants exhibiting stable hygromycin resistance phenotypes were chosen and screened on plants for pathogenicity.

\section{Characterization of REMI mutants.}

Initial characterization of the 176 REMI mutants was performed by comparing growth rates, developmental processes, and extracellular enzyme production of the mutants to the wild-type isolate L2.5.

Growth rates were determined by inoculation of a 3-mm plug of mycelia onto the center of an MS medium plate and measurement of colony diameters 72 and $120 \mathrm{~h}$ after inoculation.

To measure spore adhesion, germination, and appressorial formation, conidia from each mutant were resuspended in sterile water at a concentration of $1 \times 10^{5}$ spores $\mathrm{ml}^{-1}$ and placed into sterile $60 \times 15 \mathrm{~mm}$ polystyrene petri plates for $1 \mathrm{~h}$ at $22^{\circ} \mathrm{C}$. Supernatants were decanted and the petri plates washed five times with $10 \mathrm{ml}$ of sterile water. Spore adhesion was measured by counting the number of spores remaining attached (within four fields of vision at $\times 400$ magnification) to the petri plates. To assess spore germination and appressorial formation, $10 \mathrm{ml}$ of dilute $(\times 0.1)$ MS medium was added to the petri plates at $22^{\circ} \mathrm{C}$. Spore germination was monitored after 4 to $6 \mathrm{~h}$ and appressoria formation after 8 to $12 \mathrm{~h}$, microscopically.

Extracellular protease and cellulase enzyme activities were measured by placing a 3-mm mycelial plug at the center of a plate containing either $0.5 \%$ gelatin and $1.2 \%$ agar (for the detection of protease activity) or $0.5 \%$ carboxymethylcellulose (CMC) and $1.2 \%$ agar media (for the detection of cellulase activity). Plates were incubated at $22^{\circ} \mathrm{C}$ for 5 days and measured for extracellular enzyme activities. Gelatin plates were covered with $10 \mathrm{ml}$ of $15 \%$ mercuric chloride (wt/vol) and $20 \% \mathrm{HCL}$ (vol/vol) for $10 \mathrm{~min}$. Extracellular cellulase activity was visualized by staining CMC plates with a $1 \%$ Congo Red dye solution for $10 \mathrm{~min}$, and destaining in $1 \mathrm{M}$ $\mathrm{NaCl}$. Protease and cellulase activities were visualized as a halo of clearing surrounding the peripheral edge of the fungal colony and activities were quantitated by measuring the ratio of the clearing diameter to the fungal colony diameter.

\section{Plant pathogenicity assays and inoculation procedures.}

Primary pathogenicity screens used three anthracnosesusceptible Crimson Sweet watermelon seedlings per REMI 
transformant. Plants were grown in vermiculite for 5 to 7 days in growth chambers (95\% humidity, 12-h light regimes, $22^{\circ} \mathrm{C}$ ). Individual REMI transformants were streaked onto 5$\mathrm{ml}$ MS medium slant tubes and grown for 5 to 7 days in a 12-h light regime at $22^{\circ} \mathrm{C}$. The spores were resuspended in $5 \mathrm{ml}$ of sterile $0.07 \%$ agar solution to a final concentration of 0.5 to $1.5 \times 10^{6}$ conidia $\mathrm{ml}^{-1}$ and three watermelon seedlings were placed into each tube. Plant mortality was assessed after 7 to 10 days. Fluids were maintained at the same levels over the course of the experiments for all assays. Transformants that did not cause disease on any of the three plants were subjected to the secondary pathogenicity screening.

The secondary screening used 30 Crimson Sweet watermelon seedlings. Individual REMI mutants were streaked onto MS media plates and, after 5 days of growth, the conidia were harvested from the plates by gently scraping off the spores with a sterile glass slide. The spores were resuspended in 10 $\mathrm{ml}$ of sterile water, filtered through four layers of sterile cotton cheesecloth gauze (Fischer, Pittsburgh, PA) and centrifuged at $3,000 \times g$ for $5 \mathrm{~min}$. The supernatant was decanted and the spores resuspended in sterile water, centrifuged at $3,000 \times g$ for $5 \mathrm{~min}$, and the pellet resuspended in a final volume of $0.07 \%$ agar solution such that the conidial concentration was 1.0 to $3.0 \times 10^{6}$ conidia $\mathrm{ml}^{-1}$. Thirty watermelon seedlings were placed into $50-\mathrm{ml}$ glass beakers such that the roots and lower third of the stems were immersed into spore suspensions (1.0 to $3.0 \times 10^{6}$ conidia $\mathrm{ml}^{-1}$ ), and plant mortality was assessed after 7 to 10 days. Three plants exposed to nonpathogenic REMI transformants were assayed for colonization (see below) and REMI transformants capable of colonizing plants in the absence of disease were chosen for the tertiary screening.

The tertiary screen was conducted in the same manner as the secondary screening with the exception that, after inoculation into REMI mutant spore solutions for $48 \mathrm{~h}$, the plants were challenged with lethal concentrations $\left(1.0\right.$ to $3.0 \times 10^{6}$ conidia $\mathrm{ml}^{-1}$ ) of the wild-type C. magna isolate (L2.5) and plant mortality was assessed after 7 to 10 days. All experiments contained a negative control that consisted of 30 plants exposed to $0.07 \%$ agar solution devoid of fungal spores for 48 $\mathrm{h}$ followed by exposure to lethal concentrations of the wildtype isolate L2.5.

\section{Recovering fungi from plant tissue.}

Plants were submerged into $2.0 \%$ (vol/vol) sodium hypochlorite for 20 to 30 min with moderate agitation and rinsed with 10 to 20 volumes of sterile, distilled water. With the use of an aseptic technique, plants were cut into sections representing the lower, middle, and upper stem sections, the roots, and the cotyledons. The sections were plated onto HM selection media (containing $100 \mu \mathrm{g} \mathrm{ml}^{-1}$ of hygromycin and ampicillin) and incubated at room temperature under cool fluorescent lights for 5 to 7 days to allow for the emergence of the fungi. Identification of fungi was verified after conidiation by microscopic analysis.

\section{Molecular analysis of REMI transformants.}

Fungal genomic DNA was isolated from lyophilized mycelia grown in $100 \mathrm{ml}$ of MS liquid media as previously described (Rodriguez 1993; Freeman et al. 1993). Standard procedures were used for restriction enzyme digestion of fungal DNA (Sambrook et al. 1989). Digested and undigested DNA samples were separated on 0.5 to $0.7 \%$ agarose gels and transferred onto nitrocellulose membranes (Micron Separations, Westboro, MA) by capillary migration (Sambrook et al. 1989). Membranes were vacuum dried for $30 \mathrm{~min}$ at $80^{\circ} \mathrm{C}$ and placed into hybridization solution- $5 \times \mathrm{SSC}(1 \times \mathrm{SSC}$ is $0.15 \mathrm{M} \mathrm{NaCl}$ plus $0.015 \mathrm{M}$ sodium citrate) (Sambrook et al. 1989), $0.1 \%$ Sarkosyl, $0.02 \%$ SDS (sodium dodecyl sulfate), $0.5 \%$ blocking reagent (Boehringer-Mannheim, Indianapolis, IN)—for 2 to $12 \mathrm{~h}$ at $65^{\circ} \mathrm{C}$. Plasmid pHA1.3 and pGMR1 were linearized with HindIII and/or XhoI restriction enzymes and were radioactively labeled with the T7 QuickPrime Kit (Pharmacia Biotech, Uppsala, Sweden) according to the manufacturer's instructions. Unincorporated nucleotides were removed with Sephadex G-100 columns (Sambrook et al. 1989) and membranes were hybridized with the probe in hybridization buffer for 24 to $48 \mathrm{~h}$ at $65^{\circ} \mathrm{C}$. Membranes were then subjected to washes with decreasing salt concentrations $(2 \times, 1 \times, 0.5 \times$ $\mathrm{SSC}$ ) in the presence of $0.2 \%$ SDS. Membranes were wrapped in plastic and exposed to X-OMAT AR X-ray film (Kodak, Rochester, NY) at $-70^{\circ} \mathrm{C}$ with intensifying screens until desired exposures were achieved.

\section{Segregation analysis.}

Genetic crosses were conducted between the nonpathogenic REMI mutant R1 (mating type B) and C. magna isolate Gm16 (mating type $\mathrm{A}$ ). The mating type designations are arbitrary based on the initial description of this species (Jenkins and Winstead 1964). Crosses were established by inoculating a small mycelial plug of each mating type on opposite sides of a sterile corn leaf section placed on $1 / 10$ potato dextrose agar. Inoculated plates were incubated at $22^{\circ} \mathrm{C}$ for 2 weeks to allow for the development of perithecia. The corn leaves were obtained from young plants ( 3 weeks old), cut into sections approximately $5 \mathrm{~cm}$ long, and autoclaved. Segregation analysis was conducted by removing perithecia from the corn leaves, washing them in sterile water to eliminate contaminating conidia, and breaking them open in $100 \mu \mathrm{l}$ of sterile water on MS agar medium. After the ascospores were released, the perithecium was removed from the plate, the ascospores were spread over the surface of the medium, and the plates were incubated at $22^{\circ} \mathrm{C}$ for $24 \mathrm{~h}$. Pure cultures of the germinated ascospores were obtained by transferring them to individual plates with a scalpel.

\section{Plasmid rescue.}

The pHA1.3 transformation vector and flanking genomic DNA surrounding the insertion site were retrieved by "plasmid rescue" as follows: The genomic DNA (3 to $5 \mu \mathrm{g}$ ) of fungal transformant R1 was digested with a restriction enzyme (XhoI) that does not digest the transformation vector but does digest in the flanking genomic DNA. The digested DNA was heat treated at $80^{\circ} \mathrm{C}$ for $30 \mathrm{~min}$ to inactivate the restriction enzyme, ethanol precipitated $(\mathrm{O} .1 \mathrm{M} \mathrm{NaCl}, 2.5 \times(\mathrm{vol} / \mathrm{vol})$ 95\% ethanol), and ligated (T4 DNA Ligase, GIBCO BRL, Life Technologies, Gaithersburg, MD) in a $100-\mu$ l reaction volume. Five microliters of the ligation reaction was used for transformation into the E. coli strain DH10B (ElectroMAX cells, GIBCO BRL, Life Technologies) via electroporation with a Cell Porator (GIBCO BRL, Life Technologies) according to the manufacturer's instructions with the exception of the following modifications: transformed bacterial cells 
were grown in media devoid of ampicillin with moderate agitation at room temperature for 6 to $8 \mathrm{~h}$; bacterial cells were plated onto medium supplemented with $100 \mu \mathrm{g} \mathrm{ml}{ }^{-1}$ of ampicillin and incubated at room temperature for 24 to $48 \mathrm{~h}$ to help facilitate "plasmid rescue."

\section{Transformation of pGMR1 into C. magna L2.5.}

C. magna L2.5 protoplasts were transformed with pGMR1 in the same manner as REMI transformation (described above) with the following modifications: pGMR1 was used as the transformation vector; pGMR1 was transformed as circular and XhoI-digested plasmid DNA in the absence of restriction enzymes.

\section{ACKNOWLEDGMENTS}

We would like to thank Jed Morrel for his assistance in screening REMI mutants on plants. We would also like to thank Gayle Brown, David R. Clifton, and Alison Colwell for critical reviews of this manuscript. Special thanks to Harry Merkin for helpful discussions concerning this work. This research was supported in part by a USDA grant, a joint NSF, DOE USDA grant (R. J. R. as Co-PI), and funding from the USGS.

\section{LITERATURE CITED}

Akamatsu, H., Itoh, Y., Kodama, M., Otani, H., and Kohmoto, K. 1997. AAL-toxin-deficient mutants of Alternaria alternata tomato pathotype by restriction enzyme-mediated integration. Phytopathology 87: 967-972.

Bailey, J. A., O'Connell, R. J., Pring, R. J., and Nash, C. 1992. Infection strategies of Colletotrichum species. Pages 88-120 in: Colletotrichum: Biology, Pathology and Control. J. A. Bailey and M. J. Jegers, eds. CAB Int., Wallingford, UK.

Bolker, M., Bohnert, H. U., Braun. K. H., Gorl, J., and Kahmann, R. 1995. Tagging pathogenicity genes in Ustilago maydis by restriction enzyme-mediated integration (REMI). Mol. Gen. Genet. 248:547-552.

Brown, D. H., Jr., Slobodkin, I. V., and Kumamoto, C. A. 1995. Stable transformation and regulated expression of an inducible reporter construct in Candida albicans using restriction enzyme-mediated integration. Mol. Gen. Genet. 251:75-80.

Ciuffetti, L. M., Pope, M., Dunkle, L. D., Daly, J. M., and Knoche, H. 1983. Isolation and structure of an inactive product derived from the host-specific toxin produced by Helminthosporium carbonum. Biochemistry 22:3507-3510.

Dickman, M. B., and Patil, S. S. 1986. Cutinase deficient mutants of Colletotrichum trifolii. Curr. Genet. 14:241-246.

Freeman, S., Pham, M. H., and Rodriguez, R. J. 1993. Genotyping Colletotrichum species using a nuclear DNA repetitive element, restriction enzyme digestion patterns of $\mathrm{A}+\mathrm{T}$ rich DNA, and arbitrarily primed PCR. Exp. Mycol. 17:309-322.

Freeman, S., and Rodriguez, R. J. 1992. A rapid, reliable bioassay for pathogenicity of Colletotrichum magna on cucurbits and its use in screening for nonpathogenic mutants. Plant Dis. 76:901-905.

Freeman, S., and Rodriguez, R. J. 1993. Genetic conversion of a fungal plant pathogen to a nonpathogenic, endophytic mutualist. Science 260:75-78.

Granado, J. D., Kertesz-Chaloupkova, K., Aebi, M., and Kues, U. 1997. Restriction enzyme-mediated DNA integration in Coprinus cinereus.
Mol. Gen. Genet. 256:28-36.

Hammerschmidt, R., Lamport, D. T. A., and Muldoon, E. P. 1984. Cell wall hydroxyproline enhancement and lignin deposition as an early event in the resistance of cucumber to Cladosporium cucumerinum. Physiol. Plant Pathol. 24:43-47.

Hammerschmidt, R., Nuckles, E. M., and Kuc, J. 1982. Association of enhanced peroxidase activity and induced systemic resistance of cucumber to Colletotrichum lagenarium. Physiol. Plant Pathol. 20:73-82.

Hammond-Kosack, K. E., and Jones, J. D. G. 1996. Resistance genedependant plant defense responses. Plant Cell 8:1773-1791.

Jackson, A. O., and Taylor C. B. 1996. Plant-microbe interactions: Life and death at the interface. Plant Cell 8:1651-1668.

Jenkins, S. F., Jr., and Winstead, N. N. 1964. Glomerella magna, cause of a new anthracnose of cucurbits. Phytopathology 54:452-454.

Kang, S., and Metzenberg, R. L. 1993. Insertional mutagenesis in Neurospora crassa: Cloning and molecular analysis of the preg+ gene controlling the activity of the transcriptional activator NUC-1. Genetics 133:193-202.

Keen, N. T. 1986. Pathogenic strategies of fungi. Pages 171-188 in: Recognition in Microbe-Plant Symbiotic and Pathogenic Interactions. B. Lugtenberg, ed. Springer-Verlag, Berlin.

Kolattukudy, P. E. 1985. Enzymatic penetration of the plant cuticle by fungal pathogens. Annu. Rev. Phytopathol. 81:216-221.

Kuc, J. 1990. A case for self defense in plants in disease. Phytoparasitica 18:3-8

Kuspa, A., and Loomis, W. F. 1992. Tagging developmental genes in Dictyostelium by restriction enzyme-mediated integration of plasmid DNA. Proc. Natl. Acad. Sci. USA 89:8803-8807.

Kuspa, A., and Loomis, W. F. 1994. REMI-RFLP mapping in the Dictyostelium genome. Genetics 138:665-674.

Madamanchi, N. R., and Kuc, J. 1991. Induced systemic resistance in plants. Pages 347-362 in: The Fungal Spore and Disease Initiation in Plants and Animals. G. T. Cole and H. C. Hochs, eds. Plenum, New York.

Powell, W. A., and Kistler, H. C. 1990. In vivo rearrangement of foreign DNA by Fusarium oxysporum produced linear self-replicating plasmids. J. Bacteriol. 172:3163-3178.

Redman, R. S., Freeman, S., Clifton, D. R., Morrel, J., Brown, G. S., and Rodriguez, R. J. 1999. Biochemical analysis of plant protection afforded by a non-pathogenic endophytic mutant of Colletotrichum magna (teleomorph: Glomerella magna; Jenkins and Winstead 1964). Plant Physiol. 119:795-804.

Redman, R. S., and Rodriguez, R. J. 1994. Factors affecting the efficient transformation of Colletotrichum species. Exp. Mycol. 18:230-246.

Rodriguez, R. J. 1993. Polyphosphates present in DNA preparations from filamentous fungal species of Colletotrichum inhibit restriction endonucleases and other enzymes. Anal. Biochem. 209:1-7.

Rodriguez, R. J., and Redman, R. S. 1992. Molecular transformation and genome analysis of Colletotrichum species. Pages 47-76 in: Colletotrichum: Biology, Pathology and Control. J. A. Bailey and M. J. Jegers, eds. CAB Int., Wallingford, UK.

Sambrook, J., Fritsch, E. F., and Maniatis, T. A. 1989. Molecular Cloning: A Laboratory Manual. 2nd ed. Cold Springs Harbor Laboratory, Cold Springs Harbor, NY.

Shi, Z., Christian, D., and Leung, H. 1995. Enhanced transformation in Magnaporthe grisea by restriction enzyme mediated integration of plasmid DNA. Phytopathology 85:329-333.

Sweigard, J. A., Carroll, A. M., Farrall, L., Chumley, F. G., and Valent, B. 1998. Magnaporthe grisea pathogenicity genes obtained through insertional mutagenesis. Mol. Plant-Microbe Interact. 11:404-412.

Tu, J. C. 1985. An improved Mathur's medium for growth, sporulation and germination of spores of Colletotrichum lindemuthianum. Microbiosis 44:87-93. 